Article

\title{
Decisions of Supply Chain Considering Chain-to-Chain Competition and Service Negative Spillover Effect
}

\author{
Yucai $\mathrm{Wu} * \mathbb{C}$, Jiguang Wang $(\mathbb{D}$ and Changhong Li \\ School of Economics and Management, Shanxi University, Taiyuan 030006, China; wangjg@sxu.edu.cn (J.W.); \\ lch7320@sxu.edu.cn (C.L.) \\ * Correspondence: wuyucai1991@email.sxu.edu.cn
}

Received: 23 January 2019; Accepted: 14 March 2019; Published: 17 March 2019

check for updates

\begin{abstract}
In today's complex market competition environment, a high quality and high level of service plays a critical role in obtaining and maintaining long-term sustainable competitive advantage for enterprises and supply chains. Considering the service negative spillover effect, this paper investigates the horizontal Stackelberg competition and optimal service decision in two competing manufacturer-led supply chains. Four competitive structure models are constructed and the corresponding equilibrium solutions are obtained. By comparing the equilibrium results of four different structures, it is found that the service negative spillover effect and competition between supply chains have negative incentive effect on service providers and their supply chains. However, the chain-to-chain competition will benefit the supply chain that does not provide services from free-riding effect, which will be intensified with the intensification of competition. In addition, from the perspective of supply chain network and externality, we find that when the structure of one supply chain remains fixed and the other changes from centralized to decentralized, there will be a "double marginalization" effect. At the same time, the structural change from centralized to decentralized has certain "altruism", that is, positive network externality, so as to improve the rival's performance significantly.
\end{abstract}

Keywords: supply chain; competition; service; negative spillover effect

\section{Introduction}

Nowadays, supply chain competition has become a research hotspot in the field of management. From the perspective of a supply chain network, the supply chain should not only coordinate the vertical competition of its members, but also face the horizontal competition of the same level of external supply chain [1-4]. Moreover, there are bound to be differences in power or bargaining power in supply chain competition. Within the supply chain, for example, in vertical transactions between large manufacturers such as Apple, HP and small retailers, it is obvious that Apple and HP have more power or bargaining power compared with small retailers. Among the supply chains, for example, the coal supply chains of China Shenhua Energy, Datong Coal Mine Group and other large coal manufacturers are obviously stronger in horizontal bargaining than small coal enterprises $[5,6]$.

In today's complex and dynamic environment, the production and operation of a supply chain and its enterprises are often affected by external uncertain factors, such as facility interruption, demand interference and risk. Therefore, we believe that sustainable supply chain is becoming an appropriate analytical framework based on these factors. Traditional sustainable theory includes three aspects: economy, society and environment. However, as the dynamic environment evolves, the research perspective and focus on sustainability are also changing dynamically. In recent years, in addition to the 
above three dimensions, many scholars have extended and developed the theoretical research content and framework of sustainability to operational and supply chain integration $[7,8]$. Furthermore, some more specific secondary indicators are proposed, such as service, customer satisfaction, competition, supply chain profits, collaboration, external and internal relationship management, operational efficiency [9].

As we all know, the goal of sustainable operations and supply chain management is to realize the long-term and stable development of the supply chain or the enterprises in terms of operation and management. Based on the concept of the sustainable supply chain, this paper raises the research perspective from the previous micro level of enterprise competition to the macro level of supply chain competition. In short, there are two main purposes of this paper. On the one hand, through the study of overall supply chain structure optimization and service decision, supply chain profit and service level should be balanced to realize the integration of supply chain and achieve optimal operation efficiency so as to enhance the overall sustainable competitiveness. On the other hand, internal and external competition relations should be coordinated and stabilized to make the supply chain operate under the long-term stable structure to obtain the optimal performance. In the long run, for the entire social development, the economy and efficiency are optimized to a certain extent, which is conducive to long-term sustainability.

In fact, there are usually two types of supply chain structures: centralized and decentralized. Therefore, when considering two competing supply chains simultaneously, four different structural combinations may be encountered. Furthermore, this paper studies how the service negative spillover effects affect the decision-making behaviors of game participants in four scenarios and how negative spillover effects interact with supply chain competition. Specifically, the motivation of this paper is to analyze how the service negative spillover effect of and supply chain competition will affect the optimal performance of supply chain under different supply chain structures through game model, including the optimal service level, profit, pricing and other aspects of decision.

In order to obtain long-term sustainable competitive advantages in the complex supply chain competition, many enterprises often provide free transportation, door-to-door delivery, after-sales maintenance, free explanation, demonstration and other services to meet the personalized needs of consumers as well as improve the consumer experience and product added value. These types of services improve consumer utility and enterprises competitive advantages, but can also result in free-riding behavior or negative spillover effect $[10,11]$, which may damage the interests of service providers.

Thus, several questions arise: How does this service negative spillover affect supply chain decision-making? Is this effect different under different supply chain competition structures? Furthermore, when considering the service negative spillover effect and supply chain competition, how can the supply chain and its member enterprises make decisions to achieve optimal performance? Which supply chain structure has better performance? What are the steady-state and equilibrium solutions for each game of this complex dynamic evolutionary game? These questions have important theoretical and practical significance. In this paper, we attempt to address these questions.

Motivated by above facts and key questions, this paper aims to analyze how the choice of supply chain structure affects the profits of supply chains and their members. Meanwhile, we also focus on the impact of service negative spillover and competition on supply chain decision-making, profit and game behavior in this evolutionary game. The rest of this paper is organized as follows: Section 2 briefly provides a literature review concentrating on the supply chain-to-chain competition and service negative spillover. In Section 3, we propose the problem and competition game. The equilibriums under four supply chain structures are derived in Section 4. The comparison and analysis of equilibriums in various supply chain structures is made in Section 5. This subsection focuses on the impact of service negative spillover and degree of competition on the equilibrium solutions. The numerical experiments further analyze the influence of service negative spillover effect on the optimal 
profits of supply chain under four structures in Section 6. Finally, conclusions and future research prospects are provided in Section 7.

\section{Literature Review}

The concept of 'triple bottom line' (TBL) is widely recognized and studied since proposed by Elkington [12]. The sustainable theory includes three dimensions: economy, society and environment. There is no doubt that the classical concept of TBL of sustainability is the cornerstone of sustainable operation and supply chain management framework [13-15]. However, as the dynamic environment evolves, the research perspective on sustainability is also changing dynamically. In recent years, in addition to the above three dimensions, many scholars have extended and developed the theoretical research content and framework of sustainability to operational and supply chain integration [7-9]. Therefore, the literature review in this subsection is based on the above consideration and perspective of sustainable operations and supply chain management. We briefly review the literature on chain-to-chain competition and service spillover effect in supply chain. There are two closely related streams of research.

The first stream of research is on the external competition for two supply chains. So far, the research in this field is limited in both quantity and achievement. The seminal work on this topic is made by McGuire \& Staelin, which creatively introduces two competing suppliers offering alternative products to analysis game equilibrium of downstream vertical integration. It is found that when the competition is fierce, that is, the product is highly substitutable, the decentralized structure is the best choice for the core enterprises supply chain [16]. Similarly, Choi analyzes a supply chain system consisting of two competing manufacturers and a common retailer with linear and nonlinear demand. This paper introduces three basic power scenarios of manufacuturer-Stackelberg (MS), retailer-Stackelberg (RS) and vertical Nash (VN) [17].

The above literatures mainly focus on the competition among core firms within the supply chain rather than multiple completely independent supply chains. In recent years, some scholars think the competitive advantage of an enterprise is no longer determined by its own competitive position, but more directly affected by the competitive advantage of the supply chain $[18,19]$. Therefore, some scholars further expand into the research of competition among completely independent supply chains and some optimization models are constructed. For example, some literature uses the Cournot model to study supply chain competition issues [20-22]. However, the Cournot model has certain limitation that can usually only be applied to the scenario of duopoly competition. Consequently, more scholars study supply chain competition through other more general optimization methods and game models. Zhao \& Shi study the structuring and contract optimization between two competing supply chains composed of multiple suppliers and a single retailer. The results show that the supply chain under the decentralized structure performs better when the competition among supply chains is fierce, but the performance of the centralized supply chain is higher when the number of suppliers increases to a certain extent [23]. Moreover, Chen et al. extend this work to consider two competing supply chains and analyze the problems of information structures and pricing decisions [24]. More recently, Li et al. investigate equilibrium analysis of distribution channel structural choice in two power-imbalanced supply chains based on the above work. The results demonstrate that centralized structure is always the dominant strategy of leader supply chain, but the dominant strategy for the follower is related to product substitutability, that is, the degree of competition between supply chains [25]. Furthermore, $\mathrm{Li}$ \& $\mathrm{Li}$ investigate the chain-to-chain competition for sustainable products, indicating that centralized supply chain structure is the optimal decision when the degree of product substitution is low [26]. Lately, Wu et al. examine structural choice in two power-balanced competing supply chains based on Hotelling model and find a "double marginalization" paradox. The results show that the supply chains under pure centralization and pure decentralization perform better, and the two structures are more stable [5]. 
The other related stream is the research of the service spillover effect in the supply chain. Yan et al. study the spillover effect from online to offline sales on equilibrium strategies and think that the cross-channel spillover is fairly common and essential in practice [27]. Chen et al. investigate the impacts of an additional online-to-store channel and spillover effect on the optimal retail channel choice of a supply chain. The impact of spillover effect is discussed on the selection of retail channel, the manufacturer's profit, online retailer's profit and consumer surplus. The results reveal that the retailer is better off adding the online-to-store channel if the spillover intensity is in the intermediate range, while the manufacturer is better off adding the channel if the spillover intensity is relatively high or low. Consequently, a win-win outcome for the retailer and the manufacturer will occur when adding the online-to-store channel under medium spillover intensity. They also find that the consumer will gain more utility from buying through the online-to-store channel when the spillover intensity is at a moderate level [28]. A framework is developed to study pricing policies and retail services in a dual-channel supply chain. The optimal decisions are examined for the retail services and prices in a centralized and decentralized supply chain structure by using two-stage optimization technique and the Stackelberg game. The results indicate that retail services strongly influence the manufacturer and retailer's pricing strategies and profits [29]. Moreover, Hu \& Li consider a model mixed with retailing and e-tailing distribution channels where services and price decisions are made. The members' optimal service effort and expected profit are obtained [30]. Furthermore, Zhang et al. investigate retail services and pricing decisions in a dual-channel closed-loop supply chain model. The optimal decision conditions in integrated and decentralized supply chain are obtained by the two-stage optimization technique. The results show that changes in the level of retail services directly affected retail and wholesale prices, and there is a threshold for service level [31]. He et al. evaluate the impact of consumer free riding on carbon emissions in the product life cycle across a dual channel closed loop supply chain so that can assess the effect of governmental e-commerce tax on carbon emissions. The results illustrate that although manufacturers may gain economic benefits from consumer's free riding behavior, the total amount of carbon emissions from the entire supply chain also increases, and governmental tax on e-commerce could help to reduce consumer free riding and total carbon emissions [32].

In summary, there are certain limitations in the extant literature on supply chain competition and service spillover effects: (1) Most of the existing literatures only discuss the situation that two supply chains have equal power status in the competition, and seldom consider the situation that the power status is not equal, that is, one supply chain is the leader or the first mover, while the other supply chain is the follower. However, in fact, many enterprises or brands usually enter the market in sequence, and there are strengths and weaknesses in bargaining power. Therefore, it is of great practical significance to study the competition between supply chains with strong and weak relationships, but most of the literature has not conducted in-depth research on situation. (2) Most literatures studying service spillover effect of supply chain are based on single supply chain or dual-channel structure, analyzing the impact of spillover effects on supply chain decision-making. However, few literatures study the service spillover effects of two or more independent supply chains, and such research topic has important application background and value in reality. (3) The existing literatures on the supply chain service spillover effect majorly assume that the spillover effect is positive, whereas, the literature on the service negative spillover effect is ignored. In fact, the cases and examples of service negative spillovers of supply chain can be seen everywhere. Take the supply chains constructed by Suning and Gome, two large Chinese electrical retailers in the same competitive area, as examples. If Suning provides a certain level of personalized high value-added experience service but Gome has no service provision or low service level, it is obvious that Suning has certain advantages in attracting customers and improving demand, and it is likely to turn potential customers originally belonging to Gome to Suning. This has led to a decline in the performance of Gome on demand and profits, which is the negative spillover effect of service. However, relevant literature has paid little attention to the study of this negative spillover effect. 
In stark contrast to the above research, this paper extends the existing researches and primary contributions summarized as follows: (1) This paper considers the issue of horizontal competition between supply chains with unequal powers, that is, one supply chain is the leader and the other is the follower. Four Stackelberg competition models of centralization-centralization, decentralization-centralization, centralization-decentralization and decentralization-decentralization are constructed, and optimal decision conditions are obtained through game equilibrium solution and comparison. (2) This paper is based on two independent competitive supply chains when studying supply chain service spillover effects. The service decision problem is studied from the perspective of supply chain network. (3) This paper is different from the existing literature, assuming that the service spillover effect is negative. This assumption is also extremely consistent with the actual production operation and has significant application value and academic value. (4) For the model approach and method, most of existing papers propose a single Stackelberg/Cournot/Nash game. In contrast, we construct a new two-layer compound nested Stackelberg game model, and the game equilibriums are derived. Additionally, this might be a new supplement to future research in this field.

In conclusion, this paper attempts to answer these questions: what are the game equilibrium solutions under the four supply chain structures? Which structure has the best supply chain performance? What happens to supply chain performance when the structure changes? How does service negative service spillover affect supply chain optimal decision and service providers? What about the impact on the nonproviding party? Is the effect different in different structures? How does the intensity of competition between supply chains affect supply chain decisions? Next, we will discuss the above problems through game analysis.

\section{Problem Identification and Analysis}

Some key hypotheses and parameters are posed to construct and simplify our game model.

Firstly, we consider two horizontal competing supply chains for $i(i=1,2)$, whose bargaining power and market position are not equal, i.e., "one strong and one weak" in Stackelberg game. Without loss of generality, it is assumed that Supply Chain 1 is the leader and Supply Chain 2 is the follower in the game.

Secondly, in order to compare and analyze the service negative spillover effect in the supply chain competition network, this paper assumes that only manufacturer 1 provides services and manufacturer 2 serves as the reference group for comparison.

Finally, we assume that the products are completely inelastic, and competition is mainly reflected in product price in this model. Meanwhile, there are two types of supply chain structure in this paper: centralized and decentralized. For the two supply chains, there will theoretically be four combinations of supply chain structure, as shown in Table 1.

Table 1. Supply chain structures and symbols.

\begin{tabular}{ccc}
\hline & Supply Chain $\mathbf{2}$ is Centralized & Supply Chain $\mathbf{2}$ is Decentralized \\
\hline Supply Chain 1 is centralized & $(\mathrm{CC})$ & (CD) \\
Supply Chain 1 is decentralized & $(\mathrm{DC})$ & (DD) \\
\hline
\end{tabular}

For the convenience of research, the four supply chain structure diagrams are designed and illustrated in Figure 1. 


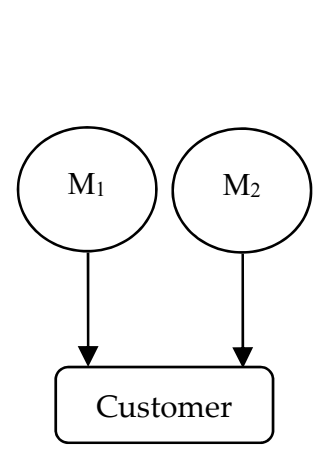

(CC)

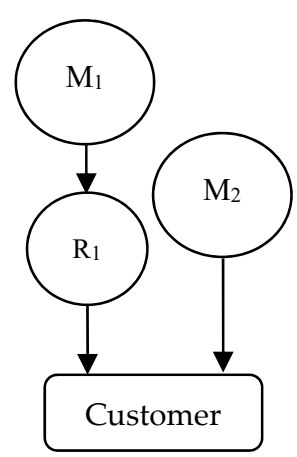

(DC)

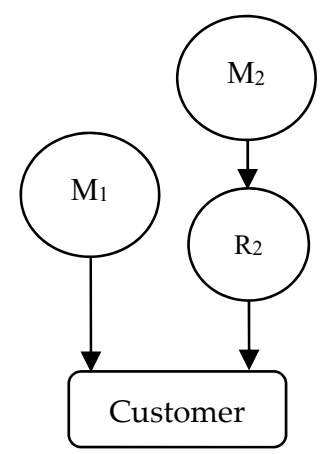

(CD)

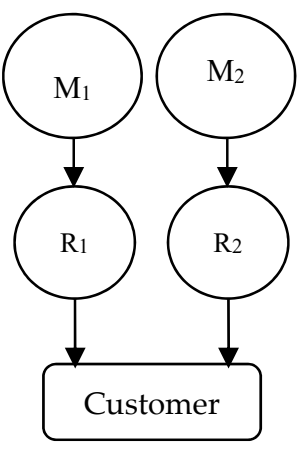

(DD)

Figure 1. Structures in Manufacuturer Stackelberg (MS) supply chain.

We define the following relevant variables and notations:

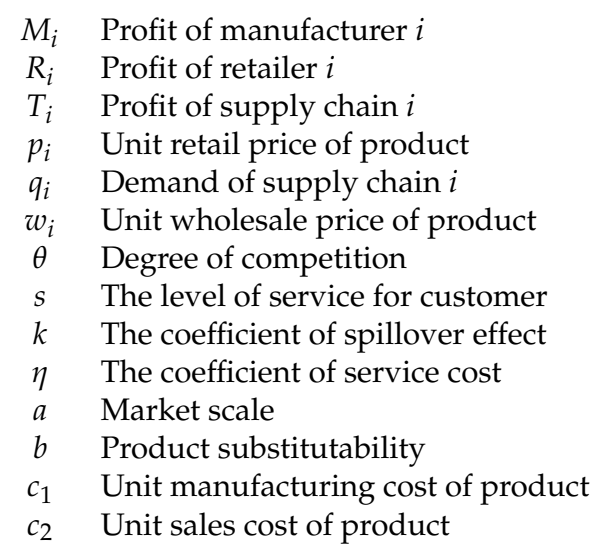

For the demand function, this model also assumes that the demand function of Supply Chain 1 is $q_{1}=a-p_{1}+\theta\left(p_{2}-p_{1}\right)+s$ and the demand function of Supply Chain 1 is $q_{2}=a-p_{2}+\theta\left(p_{1}-p_{2}\right)-$ $k s$. It should be noted that $\theta \in(0,1)$ represents the substitutability between products in the two supply chains, that is, the price change of the supply chain affects the market demand of rival supply chain when other parameters are fixed, and its value directly reflects the competition intensity between supply chains. $s$ is the service level provided by manufacturer for consumers, and it is assumed that the service cost is a quadratic function $c(s)=\frac{1}{2} \eta s^{2}$. This form has two advantages. Firstly, compared with the linear form, it is easier to form an equilibrium solution and simplify the solution process. Secondly, this hypothesis is also consistent with the actual situation, that is, the higher the service level provided by the manufacturer, the higher the cost paid, and the marginal service cost increases with the increase of the service level. Meanwhile, this form is also adopted in literature [2].

In addition, $k(0<k<1)$ represents the service negative spillover effect, that is, the service provided by Supply Chain 1 leads to the loss of customers on Supply Chain 2 . The larger the $k$ value is, the stronger the negative spillover effect will be, and the more severe the market loss of Supply Chain 2 that does not provide services will be. This hypothesis is also in line with the reality, especially in the personalized and fragmented customer market, which attaches more and more importance to the high value and high-quality service attached to the product. First-class service will obviously attract and divert more customers.

Then, horizontal Stackelberg competition, decisions of price and service are analyzed in the following parts. 


\section{Analytical Results}

In this section, we analyze the game and optimization under pure centralized structure (CC), mixed structure (DC, CD) and pure decentralized structure (DD) by means of backward recursion respectively, and finally derive equilibrium results under these four settings. We assume that Supply Chain 1 acts as the Stackelberg leader and Supply Chain 2 acts as the follower in the chain-to-chain competition. Meanwhile, the two manufacturers are the leaders and the common retailers are the followers in their respective supply chains. The leaders make decisions first because of their preemptive advantages, depending on the followers' responses.

\subsection{Pure Centralized Structures (CC)}

We firstly characterize the game behavior for two centralized supply chains controlled by two manufacturers, respectively. This section can be used as a benchmark to evaluate pricing and service decisions under pure decentralized and mixed cases to analyze the impact of different supply chain structure on the equilibrium results in the next section.

In the first case, both chains are integrated, i.e., the manufacturer and the retailer in each chain are fully cooperative to gain the whole chain's maximal profit. To simplify the model, we can use a dominant firm or manufacturer $i(i=1,2)$ to represent the members in each supply chain. Thus, the chain-to-chain competition becomes a leader-follower game between two dominant manufacturers.

The specific sequences of this game are as follows:

(1) The core manufacturer 1 determines retail price $p_{1}$ and the level of service $s$ to maximize the performance of the entire Supply Chain 1.

(2) The core manufacturer 2 makes the optimal response decision $p_{2}$ after observing the manufacturer 1 's actions to maximize the overall profit of the Supply Chain 2.

Thus, for the given retail price $p_{i}$, the profit function of supply chains can be expressed as follows:

$$
\left\{\begin{array}{l}
T_{1}=\left(p_{1}-c_{1}-c_{2}\right)\left(a-p_{1}+\theta\left(p_{2}-p_{1}\right)+s\right)-\frac{1}{2} \eta s^{2} \\
T_{2}=\left(p_{2}-c_{1}-c_{2}\right)\left(a-p_{2}+\theta\left(p_{1}-p_{2}\right)-k s\right)
\end{array}\right.
$$

Then we use backward recursion method in game theory to solve. Namely, the decisions of follower are solved first, given that the leader's decisions have been observed. The following theorem characterizes the unique pure strategy equilibrium and the players' optimal profits for the CC structure.

Theorem 1. (CC Equilibrium) When both chains are centralized, the unique pure strategy equilibrium is given by:

$$
\left\{\begin{aligned}
p_{1} & =\frac{2 a \eta\left(2+5 \theta+3 \theta^{2}\right)-\left(L_{1}-(2+(2-k) \theta)^{2}\right)\left(c_{1}+c_{2}\right)}{4 \eta\left(2+6 \theta+5 \theta^{2}+\theta^{3}\right)-(2+(2-k) \theta)^{2}} \\
p_{2} & =\frac{a L_{2}-L_{3}\left(c_{1}+c_{2}\right)}{4 \eta\left(2+6 \theta+5 \theta^{2}+\theta^{3}\right)-(2+(2-k) \theta)^{2}} \\
s & =\frac{(2+3 \theta)(2+(2-k) \theta)\left(a-c_{1}-c_{2}\right)}{4 \eta\left(2+6 \theta+5 \theta^{2}+\theta^{3}\right)-(2+(2-k) \theta)^{2}} \\
q_{1} & =\frac{\eta\left(4+14 \theta+14 \theta^{2}+3 \theta^{3}\right)\left(a-c_{1}-c_{2}\right)}{4 \eta\left(2+6 \theta+5 \theta^{2}+\theta^{3}\right)-(2+(2-k) \theta)^{2}} \\
q_{2} & =\frac{(1+\theta)\left(a-c_{1}-c_{2}\right) L_{2}}{4 \eta\left(2+6 \theta+5 \theta^{2}+\theta^{3}\right)-(2+(2-k) \theta)^{2}}
\end{aligned}\right.
$$

where $L_{1}=2 \eta\left(2+7 \theta+7 \theta^{2}+2 \theta^{3}\right), L_{2}=k^{2} \theta-2(1+\theta)-k(2+\theta)+\eta\left(4+10 \theta+5 \theta^{2}\right), L_{3}=2+6 \theta+$ $4 \theta^{2}+k^{2} \theta(1+\theta)-k\left(2+5 \theta+4 \theta^{2}\right)-\eta\left(4+14 \theta+15 \theta^{2}+4 \theta^{3}\right)$ and the corresponding optimal profits of players are as follows:

$$
\left\{\begin{array}{l}
T_{1}=\frac{\eta(2+3 \theta)^{2}\left(a-c_{1}-c_{2}\right)^{2}}{2\left(4 \eta\left(2+6 \theta+5 \theta^{2}+\theta^{3}\right)-(2+(2-k) \theta)^{2}\right)} \\
T_{2}=\frac{(1+\theta) L_{2}^{2}\left(a-c_{1}-c_{2}\right)^{2}}{\left(4 \eta\left(2+6 \theta+5 \theta^{2}+\theta^{3}\right)-(2+(2-k) \theta)^{2}\right)^{2}}
\end{array}\right.
$$




\subsection{Mixed Structures (DC)}

In this subsection, we study the structure where the leader supply chain is decentralized, while the follower is integrated. We suppose that chain 1, composed of manufacturer 1 and retailer 1 , is decentralized and chain 2 is centralized.

The specific sequences of this game are as follows:

(1) As the core enterprise in the leader supply chain, the core manufacturer 1 announces the wholesale price $w_{1}$ to retailer1 and the level of service $s$.

(2) Retailer 1 announces the retail price $p_{1}$ to maximize its own profit.

(3) The follower Supply Chain 2 decides the retail price $p_{2}$.

It is obvious that the profit of manufacturer 1 is:

$$
M_{1}=\left(w_{1}-c_{1}\right)\left(a-p_{1}+\theta\left(p_{2}-p_{1}\right)+s\right)-\frac{1}{2} \eta s^{2}
$$

and the profit of retailer 1 is:

$$
R_{1}=\left(p_{1}-w_{1}-c_{2}\right)\left(a-p_{1}+\theta\left(p_{2}-p_{1}\right)+s\right)
$$

the profit of manufacturer 2 is:

$$
M_{2}=\left(p_{2}-c_{1}-c_{2}\right)\left(a-p_{2}+\theta\left(p_{1}-p_{2}\right)-k s\right)
$$

Then, the problem is solved backwards and we can get the unique pure strategy subgame perfect equilibrium and the players' optimal profits for the DC structure.

Theorem 2 (DC Equilibrium). In hybrid structure, the unique pure strategy of subgame perfect Nash equilibrium (SPNE) is given by:

$$
\left\{\begin{aligned}
w_{1} & =\frac{\left(2 L_{1}-(2+(2-k) \theta)^{2}\right) c_{1}+4 \eta\left(2+5 \theta+3 \theta^{2}\right)\left(a-c_{2}\right)}{8 \eta\left(2+6 \theta+5 \theta^{2}+\theta^{3}\right)-(2+(2-k) \theta)^{2}} \\
p_{1} & =\frac{6 a \eta\left(2+5 \theta+3 \theta^{2}\right)-\left((2+(2-k) \theta)^{2}-2 \eta\left(2+9 \theta+11 \theta^{2}+4 \theta^{3}\right)\right)\left(c_{1}+c_{2}\right)}{8 \eta\left(2+6 \theta+5 \theta^{2}+\theta^{3}\right)-(2+(2-k) \theta)^{2}} \\
p_{2} & =\frac{a L_{4}-L_{5}\left(c_{1}+c_{2}\right)}{8 \eta\left(2+6 \theta+5 \theta^{2}+\theta^{3}\right)-(2+(2-k) \theta)^{2}} \\
s & =\frac{(2+3 \theta)(2+(2-k) \theta)\left(a-c_{1}-c_{2}\right)}{8 \eta\left(2+6 \theta+5 \theta^{2}+\theta^{3}\right)-(2+(2-k) \theta)^{2}} \\
q_{1} & =\frac{\eta\left(4+14 \theta+14 \theta^{2}+3 \theta^{3}\right)\left(a-c_{1}-c_{2}\right)}{8 \eta\left(2+6 \theta+5 \theta^{2}+\theta^{3}\right)-(2+(2-k) \theta)^{2}} \\
q_{2} & =\frac{(1+\theta) L_{4}\left(a-c_{1}-c_{2}\right)}{8 \eta\left(2+6 \theta+5 \theta^{2}+\theta^{3}\right)-(2+(2-k) \theta)^{2}}
\end{aligned}\right.
$$

where $L_{4}=k^{2} \theta-2(1+\theta)-k(2+\theta)+\eta\left(8+22 \theta+13 \theta^{2}\right), L_{5}=2+6 \theta+4 \theta^{2}+k^{2} \theta(1+\theta)-$ $k\left(2+5 \theta+4 \theta^{2}\right)-\eta\left(8+26 \theta+27 \theta^{2}+8 \theta^{3}\right)$. The corresponding optimal profits of players are given by:

$$
\left\{\begin{array}{l}
R_{1}=\frac{2 \eta^{2}(1+\theta)(2+3 \theta)^{2}\left(2+4 \theta+\theta^{2}\right)\left(a-c_{1}-c_{2}\right)^{2}}{\left(8 \eta\left(2+6 \theta+5 \theta^{2}+\theta^{3}\right)-(2+(2-k) \theta)^{2}\right)^{2}} \\
M_{1}=\frac{\eta(2+3 \theta)^{2}\left(a-c_{1}-c_{2}\right)^{2}}{2\left(8 \eta\left(2+6 \theta+5 \theta^{2}+\theta^{3}\right)-(2+(2-k) \theta)^{2}\right)} \\
M_{2}=\frac{(1+\theta) L_{4}^{2}\left(a-c_{1}-c_{2}\right)^{2}}{\left(8 \eta\left(2+6 \theta+5 \theta^{2}+\theta^{3}\right)-(2+(2-k) \theta)^{2}\right)^{2}}
\end{array}\right.
$$


and the corresponding optimal profits of the two supply chains are given by:

$$
\left\{\begin{array}{l}
T_{1}=\frac{\eta(2+3 \theta)^{2}\left(12 \eta\left(2+6 \theta+5 \theta^{2}+\theta^{3}\right)-(2+(2-k) \theta)^{2}\right)\left(a-c_{1}-c_{2}\right)^{2}}{2\left(8 \eta\left(2+6 \theta+5 \theta^{2}+\theta^{3}\right)-(2+(2-k) \theta)^{2}\right)^{2}} \\
T_{2}=\frac{(1+\theta) L_{4}^{2}\left(a-c_{1}-c_{2}\right)^{2}}{\left(8 \eta\left(2+6 \theta+5 \theta^{2}+\theta^{3}\right)-(2+(2-k) \theta)^{2}\right)^{2}}
\end{array}\right.
$$

\subsection{Mixed Structures $(C D)$}

In this scenario, we assume that chain 1 is centralized and chain 2, composed of manufacturer 2 and retailer 2, is decentralized. The specific sequences of this game are as follows:

(1) The leader supply chain 1 decides the retail price $p_{1}$ and the level of service $s$ to maximize the performance.

(2) As the core enterprise in the follower supply chain, manufacturer 2 announces the wholesale price $w_{2}$ to retailer 2 to maximize its own profit.

(3) Retailer 2 decides the retail price $p_{2}$.

It is obvious that the profit of Supply Chain 1 is:

$$
M_{1}=\left(p_{1}-c_{1}-c_{2}\right)\left(a-p_{1}+\theta\left(p_{2}-p_{1}\right)+s\right)-\frac{1}{2} \eta s^{2}
$$

the profit of retailer 2 is:

$$
R_{2}=\left(p_{2}-w_{2}-c_{2}\right)\left(a-p_{2}+\theta\left(p_{1}-p_{2}\right)-k s\right)
$$

and the profit of manufacturer 2 is:

$$
M_{2}=\left(w_{2}-c_{1}\right)\left(a-p_{2}+\theta\left(p_{1}-p_{2}\right)-k s\right)
$$

Then, the problem is solved backwards and we can get the unique pure strategy sub-game perfect equilibrium and the players' optimal profits for the CD structure.

Theorem 3 (CD Equilibrium). In hybrid structure, the unique pure strategy of SPNE is given by:

$$
\left\{\begin{aligned}
w_{2} & =\frac{\left(-3 k^{2} \theta(2+3 \theta)+k\left(8+26 \theta+24 \theta^{2}\right)+2 \eta\left(8+28 \theta+27 \theta^{2}+4 \theta^{3}\right)-8\left(1+3 \theta+2 \theta^{2}\right)\right) c_{1}+2 L_{6}\left(a-c_{2}\right)}{8 \eta\left(4+12 \theta+9 \theta^{2}+\theta^{3}\right)-(4+(4-3 k))^{2}} \\
p_{1} & =\frac{4 a \eta\left(4+11 \theta+7 \theta^{2}\right)+\left(-(4+(4-3 k) \theta)^{2}+4 \eta\left(4+13 \theta+11 \theta^{2}+2 \theta^{3}\right)\right)\left(c_{1}+c_{2}\right)}{8 \eta\left(4+12 \theta+9 \theta^{2}+\theta^{3}\right)-(4+(4-3 k) \theta)^{2}} \\
p_{2} & =\frac{3 a L_{6}+\left(3 k\left(4+9 \theta+8 \theta^{2}\right)-9 k^{2} \theta(1+\theta)-4\left(1+5 \theta+4 \theta^{2}\right)+\eta\left(8+36 \theta+45 \theta^{2}+8 \theta^{3}\right)\right)\left(c_{1}+c_{2}\right)}{8 \eta\left(4+12 \theta+9 \theta^{2}+\theta^{3}\right)-(4+(4-3 k) \theta)^{2}} \\
s & =\frac{(4+7 \theta)(4+(4-3 k) \theta)\left(a-c_{1}-c_{2}\right)}{8 \eta\left(4+12 \theta+9 \theta^{2}+\theta^{3}\right)-(4+(4-3 k))^{2}} \\
q_{1} & =\frac{\eta\left(16+60 \theta+60 \theta^{2}+7 \theta^{3}\right)\left(a-c_{1}-c_{2}\right)}{8 \eta\left(4+12 \theta+9 \theta^{2}+\theta^{3}\right)-(4+(4-3 k) \theta)^{2}} \\
q_{2} & =\frac{(1+\theta) L_{6}\left(a-c_{1}-c_{2}\right)}{8 \eta\left(4+12 \theta+9 \theta^{2}+\theta^{3}\right)-(4+(4-3 k) \theta)^{2}}
\end{aligned}\right.
$$

where $L_{6}=3 k^{2} \theta-4(1+\theta)-k(4+\theta)+\eta\left(8+20 \theta+9 \theta^{2}\right)$. The corresponding optimal profits of players are given by:

$$
\left\{\begin{array}{l}
M_{1}=\frac{\eta(4+7 \theta)^{2}\left(a-c_{1}-c_{2}\right)^{2}}{2\left(8 \eta\left(4+12 \theta+9 \theta^{2}+\theta^{3}\right)-(4+(4-3 k) \theta)^{2}\right)} \\
M_{2}=\frac{2(1+\theta) L_{6}^{2}\left(a-c_{1}-c_{2}\right)^{2}}{\left(8 \eta\left(4+12 \theta+9 \theta^{2}+\theta^{3}\right)-(4+(4-3 k) \theta)^{2}\right)^{2}} \\
R_{2}=\frac{(1+\theta) L_{6}^{2}\left(a-c_{1}-c_{2}\right)^{2}}{\left(8 \eta\left(4+12 \theta+9 \theta^{2}+\theta^{3}\right)-(4+(4-3 k) \theta)^{2}\right)^{2}}
\end{array}\right.
$$


and the corresponding optimal profits of the two supply chains are given by:

$$
\left\{\begin{array}{l}
T_{1}=\frac{\eta(4+7 \theta)^{2}\left(a-c_{1}-c_{2}\right)^{2}}{2\left(8 \eta\left(4+12 \theta+9 \theta^{2}+\theta^{3}\right)-(4+(4-3 k) \theta)^{2}\right)} \\
T_{2}=\frac{3(1+\theta) L_{6}^{2}\left(a-c_{1}-c_{2}\right)^{2}}{\left(8 \eta\left(4+12 \theta+9 \theta^{2}+\theta^{3}\right)-(4+(4-3 k) \theta)^{2}\right)^{2}}
\end{array}\right.
$$

\subsection{Decentralized Structures (DD)}

In this subsection, we study the case where both chains are decentralized. For convenience, it is assumed that the supply chain $i$ is composed of the manufacturer $i$ as the leader in Stackelberg game, and the exclusive retailer $i$ as the follower.

The specific sequences of this game are as follows:

(1) As the core enterprise in the leader supply chain, the core manufacturer 1 announces the wholesale price $w_{1}$ to retailer 1 and the level of service $s$.

(2) Retailer 1 announces the retail price $p_{1}$ to maximize its own profits.

(3) As the core enterprise in the follower supply chain, manufacturer 2 announces the wholesale price $w_{2}$ to retailer 2 to maximize its own profits.

(4) Retailer 2 decides the retail price $p_{2}$.

Obviously, the profits of manufacturers are:

$$
\left\{\begin{array}{l}
M_{1}=\left(w_{1}-c_{1}\right)\left(a-p_{1}+\theta\left(p_{2}-p_{1}\right)+s\right)-\frac{1}{2} \eta s^{2} \\
M_{2}=\left(w_{2}-c_{1}\right)\left(a-p_{2}+\theta\left(p_{1}-p_{2}\right)-k s\right)
\end{array}\right.
$$

and the profits of retailers are:

$$
\left\{\begin{array}{l}
R_{1}=\left(p_{1}-w_{1}-c_{2}\right)\left(a-p_{1}+\theta\left(p_{2}-p_{1}\right)+s\right) \\
R_{2}=\left(p_{2}-w_{2}-c_{2}\right)\left(a-p_{2}+\theta\left(p_{1}-p_{2}\right)-k s\right)
\end{array}\right.
$$

The following theorem is the unique pure strategy sub-game perfect Nash equilibrium and the players' optimal profit for the DD structure.

Theorem 4 (DD Equilibrium). When both chains are decentralized, the unique pure strategy of SPNE is given by:

$$
\left\{\begin{aligned}
w_{1} & =\frac{\left(8 \eta\left(4+13 \theta+11 \theta^{2}+2 \theta^{3}\right)-(4+(4-3 k) \theta)^{2}\right) c_{1}+8 \eta\left(4+11 \theta+7 \theta^{2}\right)\left(a-c_{2}\right)}{16 \eta\left(4+12 \theta+9 \theta^{2}+\theta^{3}\right)-(4+(4-3 k) \theta)^{2}} \\
w_{2} & =\frac{\left(k\left(8+26 \theta+24 \theta^{2}\right)-3 k^{2} \theta(2+3 \theta)+2 \eta\left(16+52 \theta+47 \theta^{2}+8 \theta^{3}\right)-2\left(1+3 \theta+2 \theta^{2}\right)\right) c_{1}+2 L_{7}\left(a-c_{2}\right)}{16 \eta\left(4+12 \theta+9 \theta^{2}+\theta^{3}\right)-(4+(4-3 k) \theta)^{2}} \\
p_{1} & =\frac{12 a \eta\left(4+11 \theta+7 \theta^{2}\right)+\left(4 \eta\left(4+15 \theta+15 \theta^{2}+4 \theta^{3}\right)-(4+(4-3 k) \theta)^{2}\right)\left(c_{1}+c_{2}\right)}{16 \eta\left(4+12 \theta+9 \theta^{2}+\theta^{3}\right)-(4-(4-3 k) \theta)^{2}} \\
p_{2} & =\frac{3 a L_{7}+\left(3 k\left(4+9 \theta+8 \theta^{2}\right)-9 k^{2} \theta(1+\theta)-4\left(1+5 \theta+4 \theta^{2}\right)+\eta\left(16+60 \theta+69 \theta^{2}+16 \theta^{3}\right)\right)\left(c_{1}+c_{2}\right)}{16 \eta\left(4+12 \theta+9 \theta^{2}+\theta^{3}\right)-(4+(4-3 k) \theta)^{2}} \\
s & =\frac{(4+7 \theta)(4+(4-3 k) \theta)\left(a-c_{1}-c_{2}\right)}{16 \eta\left(4+12 \theta+9 \theta^{2}+\theta^{3}\right)-(4+(4-3 k) \theta)^{2}} \\
q_{1} & =\frac{\eta\left(16+60 \theta+60 \theta^{2}+7 \theta^{3}\right)\left(a-c_{1}-c_{2}\right)}{16 \eta\left(4+12 \theta+9 \theta^{2}+\theta^{3}\right)-(4+(4-3 k) \theta)^{2}} \\
q_{2} & =\frac{(1+\theta) L_{7}\left(a-c_{1}-c_{2}\right)}{16 \eta\left(4+12 \theta+9 \theta^{2}+\theta^{3}\right)-(4+(4-3 k) \theta)^{2}}
\end{aligned}\right.
$$


where $L_{7}=3 k^{2} \theta-4(1+\theta)-k(4+\theta)+\eta\left(16+44 \theta+25 \theta^{2}\right)$. The corresponding optimal profits of the four players are given by:

$$
\left\{\begin{array}{l}
M_{1}=\frac{\eta(4+7 \theta)^{2}\left(a-c_{1}-c_{2}\right)^{2}}{2\left(16 \eta\left(4+12 \theta+9 \theta^{2}+\theta^{3}\right)-(4+(4-3 k) \theta)^{2}\right)} \\
R_{1}=\frac{4 \eta^{2}(4+7 \theta)^{2}\left(4+12 \theta+9 \theta^{2}+\theta^{3}\right)\left(a-c_{1}-c_{2}\right)^{2}}{\left(16 \eta\left(4+12 \theta+9 \theta^{2}+\theta^{3}\right)-(4+(4-3 k) \theta)^{2}\right)^{2}} \\
M_{2}=\frac{2(1+\theta) L_{7}^{2}\left(a-c_{1}-c_{2}\right)^{2}}{\left(16 \eta\left(4+12 \theta+9 \theta^{2}+\theta^{3}\right)-(4+(4-3 k) \theta)^{2}\right)^{2}} \\
R_{2}=\frac{(1+\theta) L_{7}^{2}\left(a-c_{1}-c_{2}\right)^{2}}{\left(16 \eta\left(4+12 \theta+9 \theta^{2}+\theta^{3}\right)-(4+(4-3 k) \theta)^{2}\right)^{2}}
\end{array}\right.
$$

and the corresponding optimal profits of the two supply chains are given by:

$$
\left\{\begin{array}{l}
T_{1}=\frac{\eta(4+7 \theta)^{2}\left(24 \eta\left(4+12 \theta+9 \theta^{2}+\theta^{3}\right)-(4+(4-3 k) \theta)^{2}\right)\left(a-c_{1}-c_{2}\right)^{2}}{2\left(16 \eta\left(4+12 \theta+9 \theta^{2}+\theta^{3}\right)-(4+(4-3 k) \theta)^{2}\right)^{2}} \\
T_{2}=\frac{3(1+\theta) L_{7}^{2}\left(-a+c_{1}+c_{2}\right)^{2}}{\left(16 \eta\left(4+12 \theta+9 \theta^{2}+\theta^{3}\right)-(4+(4-3 k) \theta)^{2}\right)^{2}}
\end{array}\right.
$$

\section{Comparison and Analyses}

This section comprehensively compares and analyzes the influence of service negative spillover and competition degree on the equilibrium solution under the four competition structures. For convenience, we use superscript " $\mathrm{CC}$ ", " $\mathrm{DC}$ ", “ $\mathrm{CD}$ " and " $\mathrm{DD}$ " to denote above four structures and use " $\mathrm{T}$ " to denote the total profit of supply chain.

\subsection{Sensitivity Analyses of Negative Service Spillover $k$}

In order to further analyze the influence of service negative spillover effect on the equilibrium solution under four competition structure of supply chains, the results shown in Table 2 are obtained at first.

Table 2. The influence of service negative spillover effect on the equilibrium solutions.

\begin{tabular}{cccccccccccc}
\hline & $\frac{\partial p_{1}}{\partial k}$ & $\frac{\partial p_{2}}{\partial k}$ & $\frac{\partial s}{\partial k}$ & $\frac{\partial w_{1}}{\partial k}$ & $\frac{\partial w_{2}}{\partial k}$ & $\frac{\partial T_{1}}{\partial k}$ & $\frac{\partial T_{2}}{\partial k}$ & $\frac{\partial M_{1}}{\partial k}$ & $\frac{\partial R_{1}}{\partial k}$ & $\frac{\partial M_{2}}{\partial k}$ & $\frac{\partial R_{2}}{\partial k}$ \\
\hline CC & - & $\mathrm{N}$ & - & $\backslash$ & $\backslash$ & - & $\mathrm{N}$ & - & $\backslash$ & $\mathrm{N}$ & $\backslash$ \\
DC & - & $\mathrm{N}$ & - & - & $\backslash$ & - & $\mathrm{N}$ & - & - & $\mathrm{N}$ & $\backslash$ \\
$\mathrm{CD}$ & - & $\mathrm{N}$ & - & $\backslash$ & - & - & $\mathrm{N}$ & - & $\backslash$ & $\mathrm{N}$ & $\mathrm{N}$ \\
$\mathrm{DD}$ & - & - & - & - & $\mathrm{N}$ & - & $\mathrm{N}$ & - & - & $\mathrm{N}$ & $\mathrm{N}$ \\
\hline
\end{tabular}

Note: "-", "N" respectively represents negative correlation and relation cannot be determined temporarily. " $\backslash$ " means that there is no such situation.

The results show there is a significant difference in the influence of service negative spillover coefficient on the optimal prices and service level decisions of the supply chain, and the influence on profit is also different under four competition models of the supply chain. Specifically, with the increase of the negative service spillover coefficient, the optimal service level and profit provided by manufacturer 1 decreased, while the retail price and overall profit of Supply Chain 1 also declined. Furthermore, when Supply Chain 1 is decentralized (i.e., DC and DD), the optimal wholesale price and the profit of retailer 1 also decrease with the increase of negative spillover coefficient.

We further analyze the main reasons leading to the above results. In Stackelberg competition between two supply chains, when the negative spillover coefficient increases, the quantity of demand loss of Supply Chain 2 that does not provide services aggravates due to the negative spillover effect. In order to ensure profit maximization, Supply Chain 2 has the incentive to reduce price (for example, in DD model). Price competition (substitution) between chains reduces the quantity of demand in Supply Chain 1. Further, Supply Chain 1 also has two countermeasures to ensure its profit maximization: first, "incremental" means lowering prices to stimulate demand, and second, "reducing costs" means 
lowering service levels to reduce service cost inputs. However, in terms of the final results, the profits of Supply Chain 1 and manufacturer 1 providing service are still being eroded. In general, the increase of negative spillover coefficient of service is unfavorable to service providers, namely Supply Chain 1 and manufacturer 1 . Therefore, the following corollary can be obtained.

Corollary 1. An increase of the service negative spillover effect has a negative incentive for the service provider and its supply chain, reducing the performance of the service provider.

This corollary suggests that the negative spillover effect of services is obviously a negative factor for the supply chain providing service, which is different from the common perception. It is generally believed that due to the positive externality or spillover effect in the supply chain network, there will be a free-riding effect for the supply chain without service, which will seriously weaken the enthusiasm of the service provider. However, it will motivate the service provider when the spillover effect is negative.

For example, Nike's high-quality service in a physical store such as demonstration experience, careful explanation and after-sales warranty will obviously enhance its influence of brand and product and customer loyalty. For other physical stores or electronic channels without services, due to negative spillover effect causes more potential customers to flow to entity stores with higher service levels. Obviously, the negative spillover effect has positive incentives for the physical store from this result.

However, this paper finds that when the bargaining power between supply chains is "one strong and one weak", the existence of negative spillover effect does not improve the enthusiasm of service providers, but has a certain negative incentive effect on them, which is not conducive to the improvement of service level. Nevertheless, the impact on the decision-making of the supply chain without service is temporarily undetermined, and it is also related to the degree of competition between the supply chain and the cost coefficient of service.

\subsection{Sensitivity Analyses of Competition Degree}

In order to further analyze the influence of competition degree between two supply chains on the equilibrium solution under four structures, and at the same time to make the results more general and avoid the interference of service negative spillover effect on the equilibrium solution, two control experiments of low spillover scenario $(k=0.5)$ and high spillover scenario $(k=1)$ are designed. This subsection focuses on the sensitivity analysis of five key decision variables $p_{1}, p_{2}, s, T_{1}$ and $T_{2}$. First assume $a=10, c_{1}=1, c_{2}=1, \eta=1$, and then assume $\theta=0.1, \theta=0.3, \theta=0.5, \theta=0.7, \theta=0.9$ in turn. The final analysis results are shown in Table 3. 
Table 3. The influence of competition degree on the equilibrium solutions.

\begin{tabular}{|c|c|c|c|c|c|c|}
\hline \multicolumn{2}{|c|}{$k=0.5$} & \multirow{2}{*}{$\begin{array}{c}\boldsymbol{\theta}=\mathbf{0 . 1} \\
8.77\end{array}$} & \multirow{2}{*}{$\begin{array}{c}\boldsymbol{\theta}=\mathbf{0 . 3} \\
7.43\end{array}$} & \multirow{2}{*}{$\begin{array}{c}\theta=0.5 \\
6.68\end{array}$} & \multirow{2}{*}{$\begin{array}{c}\boldsymbol{\theta}=\mathbf{0 . 7} \\
6.18\end{array}$} & \multirow{2}{*}{$\begin{array}{c}\boldsymbol{\theta}=\mathbf{0 . 9} \\
5.81\end{array}$} \\
\hline CC & $p_{1}$ & & & & & \\
\hline & $p_{2}$ & 4.44 & 4.72 & 4.73 & 4.66 & 4.57 \\
\hline & $s$ & 6.61 & 5.12 & 4.29 & 3.75 & 3.36 \\
\hline & $T_{1}$ & 28.30 & 24.23 & 21.85 & 20.17 & 18.85 \\
\hline & $T_{2}$ & 6.55 & 9.61 & 11.19 & 12.05 & 12.51 \\
\hline \multirow[t]{5}{*}{ DC } & $p_{1}$ & 9.32 & 8.41 & 7.80 & 7.34 & 6.97 \\
\hline & $p_{2}$ & 5.42 & 5.43 & 5.34 & 5.21 & 5.09 \\
\hline & $S$ & 2.39 & 2.01 & 1.77 & 1.60 & 1.46 \\
\hline & $T_{1}$ & 16.73 & 15.32 & 14.32 & 13.52 & 12.83 \\
\hline & $T_{2}$ & 12.92 & 15.29 & 16.71 & 17.60 & 18.15 \\
\hline \multirow[t]{5}{*}{ CD } & $p_{1}$ & 8.82 & 7.65 & 7.04 & 6.65 & 6.36 \\
\hline & $p_{2}$ & 5.67 & 6.10 & 6.16 & 6.10 & 6.00 \\
\hline & $s$ & 6.59 & 5.16 & 4.41 & 3.93 & 3.59 \\
\hline & $T_{1}$ & 29.13 & 26.50 & 25.20 & 24.33 & 23.66 \\
\hline & $T_{2}$ & 4.95 & 7.30 & 8.64 & 9.52 & 10.13 \\
\hline \multirow[t]{5}{*}{ DD } & $p_{1}$ & 9.45 & 8.77 & 8.34 & 8.02 & 7.76 \\
\hline & $p_{2}$ & 7.14 & 7.19 & 7.12 & 7.01 & 6.89 \\
\hline & $s$ & 2.40 & 2.06 & 1.85 & 1.70 & 1.58 \\
\hline & $T_{1}$ & 17.36 & 16.95 & 16.70 & 16.47 & 16.24 \\
\hline & $T_{2}$ & 9.70 & 11.68 & 13.12 & 14.24 & 16.16 \\
\hline \multicolumn{7}{|c|}{$k=1$} \\
\hline \multirow[t]{5}{*}{$\mathrm{CC}$} & $p_{1}$ & 8.54 & 7.10 & 6.36 & 5.89 & 5.54 \\
\hline & $p_{2}$ & 3.70 & 3.93 & 4.18 & 4.25 & 4.23 \\
\hline & $S$ & 6.24 & 4.52 & 3.64 & 3.09 & 2.71 \\
\hline & $T_{1}$ & 27.33 & 22.77 & 20.36 & 18.75 & 17.54 \\
\hline & $T_{2}$ & 1.33 & 4.84 & 7.14 & 8.57 & 9.47 \\
\hline \multirow[t]{5}{*}{ DC } & $p_{1}$ & 9.23 & 8.26 & 7.63 & 7.17 & 6.81 \\
\hline & $p_{2}$ & 4.92 & 5.09 & 5.08 & 5.01 & 4.92 \\
\hline & $s$ & 2.30 & 1.84 & 1.56 & 1.37 & 1.22 \\
\hline & $T_{1}$ & 16.44 & 14.81 & 13.75 & 12.95 & 12.29 \\
\hline & $T_{2}$ & 9.38 & 12.41 & 14.26 & 15.46 & 16.24 \\
\hline \multirow[t]{5}{*}{ CD } & $p_{1}$ & 8.48 & 7.18 & 6.57 & 6.21 & 5.95 \\
\hline & $p_{2}$ & 3.78 & 5.04 & 5.54 & 5.56 & 5.55 \\
\hline & $s$ & 6.04 & 4.28 & 3.43 & 2.91 & 2.55 \\
\hline & $T_{1}$ & 27.70 & 24.30 & 22.86 & 22.02 & 21.41 \\
\hline & $T_{2}$ & 1.16 & 4.01 & 5.88 & 7.12 & 8.01 \\
\hline \multirow[t]{5}{*}{ DD } & $p_{1}$ & 9.32 & 8.53 & 8.08 & 7.76 & 7.51 \\
\hline & $p_{2}$ & 6.40 & 6.71 & 6.76 & 6.72 & 6.65 \\
\hline & $s$ & 2.27 & 1.80 & 1.52 & 1.33 & 1.18 \\
\hline & $T_{1}$ & 16.92 & 16.14 & 15.77 & 15.51 & 15.28 \\
\hline & $T_{2}$ & 7.11 & 9.60 & 11.33 & 12.63 & 13.68 \\
\hline
\end{tabular}

In order to better compare and analyze the above results, we better fix one chain's structure as the control and change the other at the same time. The following findings are obtained by the analysis of Table 3.

First, under the four supply chain competition structures, the optimal service level $s$, the optimal retail price $p_{1}$ and overall profit $T_{1}$ of Supply Chain 1 gradually decrease with the increase of competition intensity $\theta$, and the overall profit $T_{2}$ of Supply Chain 2 increases, while the optimal retail price $p_{2}$ of Supply Chain 2 shows a change trend of increasing first and then decreasing.

Overall, the optimal retail price $p_{1}>p_{2}$, but the price gap is becoming smaller and smaller with the increase of the intensity of competition. When the competition degree is small, $T_{1}>T_{2}$, but the overall profit gap between the two supply chains gradually decreases with the increase of the competition intensity, even if the competition intensity is large enough in the DC structure, $T_{2}>T_{1}$ may occur. Hence, Corollary 2 is summarized as follows.

Corollary 2. When considering service negative spillover effect between supply chains, the intensification of competition has a negative incentive effect on the manufacturer providing services and its supply chain, 
which erodes their performance level, while the supply chain that does not provide services can benefit from the free-riding effect.

The above corollary further illustrates the complexity of the influence of competition intensity and service negative spillover effect between supply chains on the performance of the two supply chains. When the supply chain providing services is the leader in the leader-follower game, the more intense competition there is, the worse it will be. Therefore, the leader supply chain providing services should take some measures to reduce the intensity of inter-chain competition, so as to alleviate the adverse impact of fierce competition on it. To some extent, this corollary explains that in practice, a strong supply chain actively seeks cooperation with small and medium-sized competitors, such as reducing the erosion of its performance by competition through alliances, mergers or cross-shareholdings.

For example, in China's takeout industry, in August 2017, Eleme, which has a large market share, successfully acquired Baidu Takeaway, which is relatively weak. As a result, the market structure of the takeout industry has evolved from a three-way competition among Eleme (41.7\%), Meituan Takeout (41\%) and Baidu Takeaway (13.2\%) to a duopoly competition between Eleme (54.1\%) and Meituan Takeout (41.5\%). In terms of Eleme and Baidu Takeaway, these two strong and weak service supply chains, the competition between the two supply chains was fierce before the acquisition, business homogeneity and channel overlap were serious, and there were obvious negative spillover effects of services. However, after the acquisition, the integration of a series of channel advantages has improved the overall competitive advantage and market share, and the overall brand effect and profitability are enhanced. This result further proves the discovery of Corollary 2. That is, reducing competition is conducive to improving supply chain profit and service level.

It can also be seen from Table 3 that when the structure of Supply Chain 2 remains unchanged, the structure of Supply Chain 1 will shift from centralized to decentralized, exists $p_{1}{ }^{D C}>p_{1} C C$, $p_{1}{ }^{D D}>p_{1}{ }^{C D}, T_{1}{ }^{D C}<T_{1}{ }^{C C}, T_{1}{ }^{D D}<T_{1}{ }^{C D}$. These results show that "double marginalization" effect really appears after the structural change for Supply Chain 1. But for the Supply Chain 2, exists $T_{2}{ }^{D C}>T_{2}{ }^{C C}, T_{2}{ }^{D D}>T_{2}{ }^{C D}$, reflecting that the structural change in the leader supply chain will produce positive externalities to the follower supply chain so as to improve its performance. Similarly, when the structure of Supply Chain 1 remains unchanged, the structure of Supply Chain 2 changes from centralized to decentralized, we find $p_{2}{ }^{C D}>p_{2}{ }^{C C}, p_{2}{ }^{D D}>p_{2}{ }^{D C}, T_{2}{ }^{C D}<T_{2}{ }^{C C}, T_{2}{ }^{D D}<T_{2}{ }^{D C}$. It also shows that the structural change in Supply Chain 2 has dual marginalization effects. For Supply Chain 1, there is $T_{1}{ }^{C D}>T_{1} C C, T_{1}{ }^{D D}>T_{1}{ }^{D C}$, indicating that the structure change of follower supply chain will also produce positive externalities to the leader one. Positive externalities will be generated for the leader supply chain. Therefore, the following corollary can be obtained as follows.

Corollary 3. In Stackelberg competition between two supply chains, when the structure of one supply chain remains unchanged and another supply chain changes from centralized to decentralized, there will be double marginalization effect and positive externality, which will benefit to its rival.

This corollary is clearly counterintuitive to our general knowledge. Classical double marginalization theory holds that the overall profit of decentralized supply chain is lower than the centralized due to members' selfishness and competitive behavior. However, this model proves that structural change from centralized to decentralized has a certain "altruism", that is, network externality will improve the performance of rival supply chain, especially with the consideration of the inter-chain competition and game. Corollary 3 is a "double marginalization" paradox that differs from the understanding of internal competition in a single supply chain.

In addition, the results in Table 3 also indicate that under the four supply chain competition structures, the service level $s$, retail price $p_{1}$ and overall profit $T_{1}$ of the experimental group with high service negative spillover effect are smaller than those of the group with low spillover effect, which further verified the conclusion of Corollary 1 . 


\section{Numerical Experiments}

In order to further analyze the influence of service negative spillover effect on the optimal profits of supply chains, this section compares the profits and change trends of Supply Chain 1 and Supply Chain 2 under CC, DC, CD and DD competition structures. Without loss of generality, we suppose $a=10, c_{1}=1, c_{2}=1, \eta=1$ and $\theta=0.5$. The overflow coefficient $k$ will change from 0 to 1, and observations will be made on how the changes affect the profits of the two supply chains. The experimental results are shown in Figures 2 and 3.

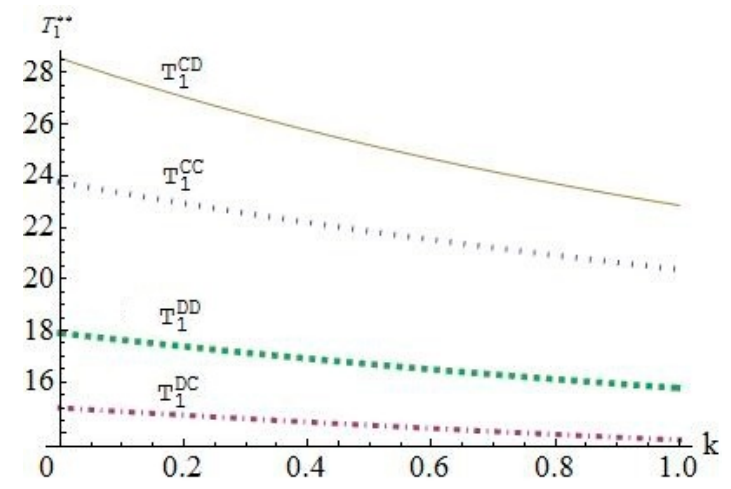

Figure 2. The profits of Supply Chain 1 changes with negative spillover effect.

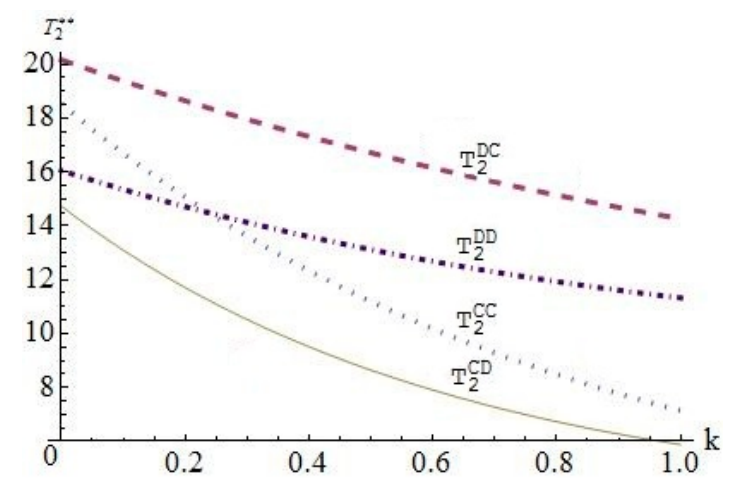

Figure 3. The profits of Supply Chain 2 changes with negative spillover effect.

Three insights can be briefly extrapolated from the figures above.

First, under four different supply chain competition structures, the negative service spillover coefficient has different effects on the overall profits of the supply chains. As a whole, the profits of the leader Supply Chain 1 providing services decrease with the increase of $k$ in four competitive structures in Figure 2. This result verifies some conclusions of Table 3 and Corollary 1, namely, the increase of negative service spillover coefficient has a negative incentive effect on Supply Chain 1 providing services. At the same time, the profits of follower Supply Chain 2 also decreases with the increase of service negative spillover effect under the four competitive structures in Figure 3. The results show that when the negative spillover effect of services increases, the follower Supply Chain 2 that does not provide services will experience a decline in its overall profit due to the negative spillover effect. The main reason is that the increase of negative spillover effect will aggravate the loss of market demand of Supply Chain 2 and thus erode its overall performance.

Second, Figure 2 shows the existence of $T_{1} D C<T_{1}{ }^{C C}$ and $T_{1}{ }^{D D}<T_{1}{ }^{C D}$, indicating that when the structure of Supply Chain 2 remains unchanged, the structural change of Supply Chain 1 from centralized to decentralized reduces the overall profit of its own supply chain, resulting in double marginalization effect. Similarly, $T_{2}{ }^{C D}<T_{2}{ }^{C C}$ and $T_{2}{ }^{D D}<T_{2}{ }^{D C}$ are found in Figure 3, indicating that when the structure of Supply Chain 1 remains unchanged, the structural change of Supply Chain 2 also produces double marginalization effect. The findings also correspond to some of the results in 
Table 3. The comprehensive conclusion shows that when the structure of competitive supply chain is unchanged, the centralized structure is the dominant strategy of the supply chain.

Finally, it is found that $T_{1}{ }^{C D}>T_{1} C C, T_{1} D D>T_{1} D C$ in Figure 2 and $T_{2}{ }^{D C}>T_{2} C C, T_{2}{ }^{D D}>T_{2}{ }^{C D}$ in Figure 3. Which reflects that when the structure of rival supply chain remains unchanged, the structural change from centralized to decentralized of the supply chain will generate positive externalities and promote the improvement of the performance of the rival. This result further verifies the findings of Table 3 and Corollary 3, indicating that in the chain-to-chain competition, the structural change of one supply chain from centralized to decentralized has a certain degree of "altruism", which is conducive to the improvement of the performance of the other supply chain. This finding verifies the conclusion of literature [5] in the competition between two power-equal supply chains. Together, the structural change of the supply chain from centralized to decentralized can always benefit the rival regardless of the power and status of the two competitive supply chains.

\section{Discussion and Conclusions}

Considering the Stackelberg competition and service negative spillover effect between two manufacturer-led supply chains, this paper establishes CC, DC, CD and DD competition models to study the optimal service decision and competition problem, and the game equilibrium solutions under the four structures are obtained through optimization. The main conclusions in this paper are:

(1) The service negative spillover effect has a negative incentive effect on the supply chain providing services, that is, the optimal profit and service provided by the manufacturer decline with the increase of the service negative spillover effect, and the retail price and overall profit of the supply chain also decline.

(2) From the perspective of the supply chain network and competition, shifting from centralized to decentralized structure has a certain "altruism", namely when a supply chain structure changes from centralized to decentralized, it will exert a double marginalized effect, at the same time produce positive externalities and promote the rival supply chain performance to increase significantly. This conclusion is consistent with the positive externalities obtained in literature [5] under Nash competition between supply chains. However, the difference is that the performance of the centralized structure in the context of Stackelberg competition with service negative spillover effect considered in this paper is higher than that of the decentralized one, while the performance of the decentralized supply chain in literature [5] is higher. The reason for the different results is likely to be the different power structure settings of the two supply chains, that is, the power asymmetry in this paper as opposed to the power equivalence in literature [5].

(3) Competition between supply chains has a negative incentive effect on the manufacturer providing services and its supply chain, while it will exert a certain free-riding effect on the supply chain and the member enterprises that do not provide services and benefit them. Moreover, the free-riding effect becomes more and more obvious with the increase of competition.

Furthermore, this article is an expansion and extension of our previous study [5] which provided a basic research framework for this paper. In addition to the conclusions, other main differences and connections between the two articles are summarized as follows:

(1) This paper investigates the influence of service negative spillover effect and supply chain competition on the game equilibrium solution. The motivation and decision goal of this paper is to optimize the service level and profit level considering the competition between supply chains and negative spillover effect. While the previous paper does not consider the service factor but focuses on the impact of chain-to-chain competition on the choice of supply chain structure.

(2) This paper takes two competing supply chains with imbalanced power as the research object, while the previous one is based on the setting scenario of two competitive supply chains with equal power. 
(3) The research method and game model are completely different. In this paper, there is an obvious sequence in the game orders and decision-making actions inside and outside the supply chain. Therefore, the game model is a two-layer composite Stackelberg model. However, in the previous paper, enterprises in the supply chain have a sequence of decision, while the two supply chains act simultaneously in the game due to the equivalence of power. Therefore, it is a Stackelberg-Nash composite game based on the Hotelling model.

Therefore, based on the above discussion and conclusions, two vital managerial implications and suggestions in this paper are as follows:

(1) In the competition of supply chain, the service negative spillover effect should be reduced to encourage the supply chain or its member enterprises to improve the service level. In practice, we can avoid too much investment in homogeneous services and products. Instead, we should put ourselves in the perspective of customers and combine consumption scenarios, innovative experience and advantages of the supply chain to provide more personalized and high-value services that are different from competitors, so as to improve consumer experience and utility. At the same time, it will also improve the performance level of service providers.

(2) In actual operations management, supply chains and their member enterprises should avoid drastic competition in order to reduce its negative effect. For example, it can realize the transformation from competition to cooperation by means of horizontal integration such as contract, cross-shareholding or merger, and integrate the advantages of each channel, brand and marketing. Meanwhile, a reasonable incentive mechanism can be designed to share the service cost and profit growth brought by the service, so as to improve the performance of the supply chains.

In fact, in addition to the damage to the economic performance of enterprises, the fierce vicious competition among enterprises usually also causes public opinion events, environmental emergencies. At the same time, the service negative spillover effect in the supply chain-to-chain competition is not conducive to service providers to actively improve service levels and quality. In the long run, it is not conducive to the improvement of consumer satisfaction and the sustainability of the supply chain. Starting from the economic perspective of the triple bottom line (TBL) of sustainability, this paper can ultimately avoid the negative impact of the other two social and environmental dimensions, so as to improve the sustainability of enterprises and supply chains.

The conclusions and management implications of this paper are not only valuable for enterprise decision makers at the micro level. For macro government policy makers, they can also formulate reasonable policies for industry development according to our conclusions and erect and maintain an open, equal and fair system of competition rules, which can transfer vicious competition into benign competition. Further, we must avoid the negative spillover effect in the industry, so as to achieve the optimal equilibrium in the competition and ultimately promote the sustainable development of the entire society.

There are several future research directions. This paper takes the manufacturer-oriented supply chains as the research object, and can further study the retailer-led supply chain competition in the future to compare and verify the conclusions of this paper. The situation of power parity between supply chains can also be considered to improve this kind of research, so as to provide more comprehensive theoretical guidance for decision-making and practice of supply chain service level.

Author Contributions: Y.W. and J.W. designed the research and game model. Y.W. and C.L. discussed the optimization method. Y.W. designed numerical experiment and wrote the paper. All authors read and discussed the final manuscript.

Funding: This research was funded by the MOE (Ministry of Education in China) Project of Humanities and Social Sciences (grant number 16YJC630116).

Acknowledgments: This work can be published thanks to many reviewers and editors for their outstanding and valuable suggestion and help. 
Conflicts of Interest: The authors declare no conflicts of interest.

\section{References}

1. Choi, S.C. Price competition in a duopoly common retailer channel. J. Retail. 1996, 72, 117-134. [CrossRef]

2. Tsay, A.; Agrawal, N. Channel dynamics under price and service competition. Manuf. Serv. Oper. Manag. 2000, 2, 372-391. [CrossRef]

3. Bernstein, F.; Federgruen, A. Decentralized supply chains with competing retailers under demand uncertainty. Manag. Sci. 2005, 51, 18-29. [CrossRef]

4. Zhao, X.; Atkins, D. Newsvendors under simultaneous price and inventory competition. Manuf. Serv. Oper. Manag. 2008, 10, 539-546. [CrossRef]

5. Wu, Y.; Wang, J.; Li, C.; Su, K. Optimal supply chain structural choice under horizontal chain-to-chain competition. Sustainability 2018, 10, 1330. [CrossRef]

6. Wang, J.; Wang, A.; Wang, Y. Markup pricing strategies between a dominant retailer and competitive manufacturers. Comput. Ind. Eng. 2013, 64, 235-246. [CrossRef]

7. Das, D. Development and validation of a scale for measuring sustainable supply chain management practices and performance. J. Clean. Prod. 2017, 164, 1344-1362. [CrossRef]

8. Das, D. The impact of sustainable supply chain management practices on firm performance: Lessons from Indian organizations. J. Clean. Prod. 2018, 203, 179-196. [CrossRef]

9. Reefke, H.; Sundaram, D. Key themes and research opportunities in sustainable supply chain management-Identification and evaluation. Omega 2017, 66, 195-211. [CrossRef]

10. Xing, D.; Liu, T. Sales effort free riding and coordination with price match and channel rebate. Eur. J. Oper. Res. 2012, 219, 264-271. [CrossRef]

11. Liu, Y.; Ding, C.; Fan, C. Pricing decision under dual-channel structure considering fairness and free-riding behavior. Discrete. Dyn. Nat. Soc. 2014, 2, 1-10. [CrossRef]

12. Elkington, J. Enter the Triple Bottom Line; Earthscan: London, UK, 2004; pp. 1-16.

13. Carter, C.R.; Easton, P.L. Sustainable supply chain management: Evolution andfuture directions. Int. J. Phys. Distrib. Logist. Manag. 2011, 41, 46-62. [CrossRef]

14. Carter, C.R.; Rogers, D.S. A framework of sustainable supply chain management: Moving toward new theory. Int. J. Phys. Distrib. Logist. Manag. 2008, 38, 360-387. [CrossRef]

15. Winter, M.; Knemeyer, A.M. Exploring the integration of sustainability and supply chain management. Int. J. Phys. Distrib. Logist. Manag. 2013, 43, 18-38. [CrossRef]

16. McGuire, T.W.; Staelin, R. An industry equilibrium analysis of downstream vertical integration. Manag. Sci. 1983, 2, 161-191. [CrossRef]

17. Choi, S.C. Price competition in a channel structure with a common retailer. Manag. Sci. 1991, 10, $271-296$. [CrossRef]

18. Rice, J.B.; Hoppe, R.M. Supply chain vs. supply chain competition. Supply Chain. Manag. Rev. 2001, 29, 46-54.

19. Lakhal, S.; Martel, A.; Kettani, O. On the optimization of supply chain networking decisions. Eur. J. Oper. Res. 2007, 129, 259-270. [CrossRef]

20. Majumder, P.; Srinivasan, A. Leadership and competition in network supply chains. Manag. Sci. 2008, 54, 1189-1204. [CrossRef]

21. Albert, Y.H.; Tong, S. Contracting and information sharing under supply chain competition. Manag. Sci. 2008, 54, 701-715.

22. Fang, Y.; Shou, B. Managing supply uncertainty under supply chain Cournot competition. Eur. J. Oper. Res. 2015, 243, 156-176. [CrossRef]

23. Zhao, X.; Shi, C. Structuring and contracting in competing supply chains. Int. J. Prod. Econ. 2011, 134, 434-446. [CrossRef]

24. Chen, K.; Liang, J.; Li, J. Information structures and pricing decisions in competing supply chains. J. Syst. Sci. Syst. Eng. 2012, 21, 226-254. [CrossRef]

25. Li, B.; Zhou, Y.; Wang, X. Equilibrium analysis of distribution channel structures under power imbalance and asymmetric information. Int. J. Prod. Res. 2013, 51, 2698-2714. [CrossRef] 
26. Li, X.; Li, Y. Chain-to-chain competition on product sustainability. J. Clean. Prod. 2016, 112, $2058-2065$. [CrossRef]

27. Yan, Y.; Zhao, R.; Liu, Z. Strategic introduction of the marketplace channel under spillovers from online to offline sales. Eur. J. Oper. Res. 2017, 267, 65-77. [CrossRef]

28. Chen, L.; Nan, G.; Li, M. Adding the online-to-store channel to supply chain: Impact of spillover effect. Soc. Sci. Ele. Pub. 2018. Available online: https:/ / ssrn.com/abstract=3202600 (accessed on 18 December 2018).

29. Dan, B.; Xu, G.; Liu, C. Pricing policies in a dual-channel supply chain with retail services. Int. J. Prod. Econ. 2012, 139, 312-320. [CrossRef]

30. Hu, W.; Li, Y. Retail service for mixed retail and E-tail channels. Ann. Oper. Res. 2012, 192, 151-171. [CrossRef]

31. Zhang, Z.; Wang, Z.; Liu, L. Retail services and pricing decisions in a closed-loop supply chain with remanufacturing. Sustainability 2015, 7, 2373-2396. [CrossRef]

32. He, R.; Xiong, Y.; Lin, Z. Carbon emissions in a dual channel closed loop supply chain: The impact of consumer free riding behavior. J. Clean. Prod. 2016, 134, 384-394. [CrossRef]

(C) 2019 by the authors. Licensee MDPI, Basel, Switzerland. This article is an open access article distributed under the terms and conditions of the Creative Commons Attribution (CC BY) license (http:/ / creativecommons.org/licenses/by/4.0/). 